\title{
Importance of Water-Volume on the Release of Microplastic Fibers from Laundry
}

Kelly, Max R.; Lant, Neil J.; Kurr, Martyn; Burgess, J. Grant

\section{Environmental Science and Technology}

DOI:

10.1021/acs.est.9b03022

Published: 15/10/2019

Peer reviewed version

Cyswllt i'r cyhoeddiad / Link to publication

Dyfyniad o'r fersiwn a gyhoeddwyd / Citation for published version (APA):

Kelly, M. R., Lant, N. J., Kurr, M., \& Burgess, J. G. (2019). Importance of Water-Volume on the Release of Microplastic Fibers from Laundry. Environmental Science and Technology, 53(20), 11735-11744. https://doi.org/10.1021/acs.est.9b03022

\footnotetext{
Hawliau Cyffredinol / General rights

Copyright and moral rights for the publications made accessible in the public portal are retained by the authors and/or other copyright owners and it is a condition of accessing publications that users recognise and abide by the legal requirements associated with these rights.

- Users may download and print one copy of any publication from the public portal for the purpose of private study or research.

- You may not further distribute the material or use it for any profit-making activity or commercial gain

- You may freely distribute the URL identifying the publication in the public portal ?
}

Take down policy

If you believe that this document breaches copyright please contact us providing details, and we will remove access to the work immediately and investigate your claim. 
This document is confidential and is proprietary to the American Chemical Society and its authors. Do not copy or disclose without written permission. If you have received this item in error, notify the sender and delete all copies.

\section{The Importance of Water-Volume on the Release of Microplastic Fibres from Laundry}

\begin{tabular}{|r|l|}
\hline Journal: & Environmental Science \& Technology \\
\hline Manuscript ID & es-2019-030225.R2 \\
\hline Manuscript Type: & Article \\
\hline Date Submitted by the & $\mathrm{n} / \mathrm{a}$ \\
\hline Complete List of Authors: & $\begin{array}{l}\text { Kelly, Max; Newcastle University, School of Natural and Environmental } \\
\text { Sciences } \\
\text { Lant, Neil; Procter and Gamble Newcastle Innovation Centre, } \\
\text { Kurr, Martyn; Newcastle University, School of Natural and Environmental } \\
\text { Sciences } \\
\text { Burgess, J Grant; Newcastle University, School of Natural and } \\
\text { Environmental Sciences }\end{array}$ \\
\hline
\end{tabular}

\section{SCHOLARONE ${ }^{\text {m }}$ Manuscripts}


*Corresponding author: grant.burgess@newcastle.ac.uk 


\section{ABSTRACT:}

18 The influence of laundry washing parameters on the release of microfibres (MF) from 19 polyester textiles was studied. These fibres are an important type of microplastic pollution. 20 However, the factors which affect MF release during laundry, are poorly understood and 21 more rigorous methods for quantifying this release are needed. A novel method was 22 therefore developed using a tergotometer with eight $(1000 \mathrm{~mL})$ washing vessels and the

23 CIELab colour space measure of lightness $\left(L^{*}\right) . L^{*}$ was related to the mass of released MFs by creating a calibration curve to quantify the amounts of MFs released from textiles during washing. This method was used to investigate the effect of water-volume, agitation, temperature, and duration of the wash on MF release. Counter-intuitively, increased watervolume, characteristic of European 'delicate' cycles, resulted in the greatest release of MFs. Full-scale testing was then carried out using domestic washing machines with real consumer cycles to determine the effect of cycle type on MF release. In the first wash, delicate wash cycles released 800,000 more MFs (94 mg/kg) per wash than a lower water-volume standard wash and also increased MF release in subsequent washing cycles $(P<0.05)$. These results indicate that a high water-volume-to-fabric ratio is the most influential factor for MF release, rather than agitation as previously thought. Therefore consumers can reduce MF release by avoiding high water-volume washes (delicate cycles), transitioning to appliances that use a lower water-volume (North American high-efficiency washing machines), and ensuring full wash loads are used. 


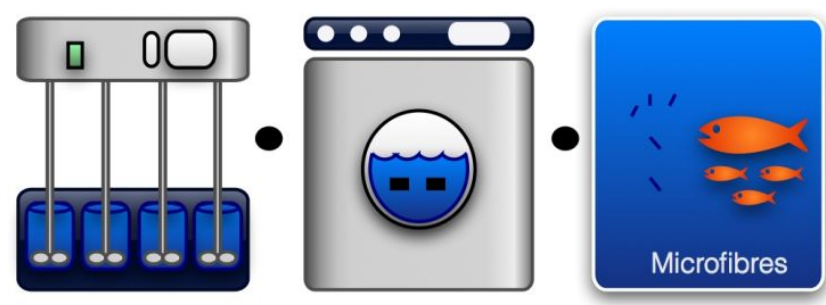

37 


\section{INTRODUCTION}

Alongside climate change and the overexploitation of natural resources, plastic pollution is one of the most problematic anthropogenic impacts on the environment. ${ }^{1}$ The environmental consequences of meso- $(5-20 \mathrm{~mm})$ and macro- $(>20 \mathrm{~mm})$ plastic ${ }^{2}$ pollution for large marine organisms have been well-documented. ${ }^{3-6}$ More recently, the impacts of microplastic $(<5$ $\mathrm{mm})^{7}$ pollution are also being investigated. ${ }^{8-10}$

Primary microplastics include manufactured microplastics such as, cosmetic microbeads ${ }^{11}$ and textile MFs, ${ }^{12}$ whereas secondary microplastics result from the breakdown of larger plastic debris. ${ }^{13}$ Synthetic MFs can be ingested by a range of marine life including commercially available fish and bivalves, ${ }^{14-15}$ crustaceans, ${ }^{16}$ non-commercial fish, ${ }^{17-18}$ birds, ${ }^{19}$ and worms. ${ }^{20}$ Once ingested, MFs can lead to reduced food consumption and energy availability, ${ }^{21}$ as well as increased mortality, at least in the laboratory. ${ }^{22-23}$ MFs have a global distribution from rivers ${ }^{24}$ to the ocean surface, ${ }^{25}$ and are found to pollute even the deepest ocean trenches. ${ }^{26-27}$ Major sources of global primary microplastic pollution include car tyres ${ }^{28}$ and synthetic MFs from clothing, ${ }^{29-32}$ which can enter the environment through waste water treatment plants from laundry of synthetic textiles. ${ }^{33-34}$

Laundering textiles can release $500,000^{35}$ to over six million ${ }^{36}$ MFs for synthetic garments and up to 13 million MFs from cotton garments per wash. ${ }^{37}$ Over 42 million tonnes of synthetic fibres are produced each year by the clothing industry ${ }^{38}$ with polyester dominating production (approximately $80 \%$ ). ${ }^{39-40}$ In addition to synthetic MFs, anthropogenic natural fibres are also released from laundering and can persist in and pollute aquatic environments. ${ }^{41-43}$ Therefore, it is important to target the laundry process to try and reduce its impact on the environment. 
61 To understand the factors that affect the release of MFs during laundry, reliable and

62

63

64

65

66

67 reproducible methods for their quantification are needed. A wide range of methods including laboratory-scale $\mathrm{e}^{36,44-46}$ to full-scale washing machines ${ }^{32,35,37,47-50}$ or a combination of both ${ }^{51-}$ 52 have been used to study MF release during laundry, leading to large disparities in the literature and a general lack of understanding of the mechanisms of MF release. Methods often do not reflect real domestic laundry conditions; for example, the use of steel balls during washing, ${ }^{36,44-46,51-52}$ is unlikely to represent real world textile interactions. For quantification of MF release, optical ${ }^{44,46,49}$ and electron microscopy, ${ }^{36,51}$ and binary image analysis ${ }^{45}$ have been used. Microscopy can require scaling which incorrectly assumes MFs are homogenously distributed across filters (used to collect MFs) leading to significant inaccuracies. Binary image analysis ${ }^{45}$ does not account for overlapping fibres, resulting in an underestimation of fibre quantities. Consequently, it is difficult to make comparisons between these studies. With larger scale studies the variability of methods is also pronounced. When investigating the effect of repeated washing cycles as a proxy for garment age on MF release, Sillanpää and Sainio, ${ }^{37}$ reported a roughly $90 \%$ decrease in MF release in the latter cycles. Conversely, Hartline et al. ${ }^{47}$ reported that older garments release more MFs when using a 24 hour continuous wash cycle to represent garment aging. Similarly, there are mixed observations on the effects of detergent on MF release. Napper and Thompson ${ }^{35}$ found that the presence of detergent generally increased MF release, in line with De Falco et al. ${ }^{36}$ In contrast, Pirc et al. ${ }^{48}$ reported detergent had no significant effect on MF release.

In addition to detergent and garment age, other studies have investigated fabric type, ${ }^{35,37}$ 49-50, 52 filter size, ${ }^{46-47,}$ 50-51 water hardness, $^{36}$ fabric softener, ${ }^{35-36,48}$ temperature, ${ }^{35-36,45,49,52}$ and type of washing machine $32,47,49$ with equally variable results (Table S1). However, factors affecting hydrodynamic forces on textiles such as water-volume, have not been studied. High 
water-volume and lower levels of drum rotation (mechanical agitation) are characteristic features of a "delicate" wash cycle in European-style front-loading washing machines designed to protect sensitive garments from mechanical damage such as pilling. ${ }^{53}$ In the US, a delicate cycle also uses a lower agitation and spin speeds. However these machines often use twice the water-volume (64 L in the main wash) compared to high-efficiency machines. ${ }^{54-}$ ${ }^{55}$ Given the high levels of public concern about microplastics, best practices for mitigating MF release are increasingly being provided by consumer organisations and media groups but often without robust scientific data. ${ }^{56-57}$ For example, consumers are being encouraged to use delicate washes to reduce MF release, with no practical evidence to support it. ${ }^{53,56-57}$ Therefore, in order to provide data which might be useful in justifying positive changes in consumer behaviour, we developed a novel small-scale method to accurately quantify MF release using a measure of lightness from black to white $\left(L^{*}\right) .{ }^{58}$ Measurement of colour was preferred over microscopy to quantify MFs, as released MFs can be very small and can form clusters on the surface of filter paper making them difficult to count due to overlapping fibres. By using $L^{*}$, the concentration of black MFs more accurately correlates with colour as more fibres result in a darker value and therefore overlapping fibres can be accounted for. $L^{*}$ offers a very precise measure of MFs as $L^{*}$ is calculated for every pixel across the filter image. By relating $L^{*}$ to known masses of MFs using a calibration curve, the mass of released MFs can be experimentally measured. This method was then used to investigate the effect of watervolume, agitation, temperature, and wash duration on the release of polyester MFs and to then confirm if these experimental observations were relevant to real consumer domestic washing cycles. We hypothesised that different washing cycles would release different amounts of MFs. 


\section{MATERIALS AND METHODS}

A novel small-scale method was developed (Figure 1) using a tergotometer, which is a

110 benchtop device comprising of eight $(1000 \mathrm{~mL})$ washing vessels that simulate full-scale domestic washing ${ }^{59-61}$ (Copley, Nottingham, U.K.) (Figure S1) and was used to characterise the

112 parameters affecting MF release. For large-scale studies, different washing cycles were performed using four front-loading washing machines (Miele ${ }^{\circledR}$, model: W3622) to determine

114 the effects of real consumer cycles on MF release. Tap water (Northumbrian Water, United 115 Kingdom) was used with a water hardness ranging from $113-128 \mathrm{mg} / \mathrm{L}$ (concentration of 116 cations) throughout all testing.

117 Textile. In all testing, black $100 \%$ textured polyester T-shirts (Fruit of the Loom ${ }^{\circledR}$, code: 118 61390) were used (Table 1). For the small-scale studies, the T-shirts were cut into $5 \times 5 \mathrm{~cm}$ 119 swatches using a laser cutter (HPC laser Ltd, model: LS1290) to seal the edges and prevent 120 uncontrolled MF release from the cut edge, removing the need for serging (overlocking).

122 Table 1. Physical properties of the textile.

\begin{tabular}{ccccc} 
Textile & Structure & Yarn & Mass $\left(\mathrm{g} / \mathrm{m}^{2}\right)$ & SEM \\
\hline & & & & \\
$100 \%$ Polyester & Knit & Filament & & \\
& & &
\end{tabular}


Small-scale washing procedure and microfibre collection. Textile swatches $(20 \pm 0.10 \mathrm{~g}$,

125

126

127 measured to two decimal places) were washed in the tergotometer steel pots with bidirectional mechanical agitation (Copley, Cat. No. 6401+6403). Tests consisted of four treatments washed over four cycles with four washing runs per cycle, resulting in four treatment repeats for each cycle (Table 2 and 3; Figure S2). Agitation (RPM) and watervolume were tested to determine the impact of the two parameters characteristic of domestic delicate cycles that use an increased water-volume-to-fabric (mass) ratio. All treatments were undertaken at $30^{\circ} \mathrm{C}$ with $0.5 \mathrm{~mL}$ Ariel ${ }^{\circledR}$ liquid for one hour including a single three-minute rinse using the same volume of water as the main wash (Table 2). The use of the same amounts of detergent was carried out deliberately to ensure the two methods were qualitatively similar; generally in domestic use, the same volumes of detergent are added to the washing machine independent of cycle type. ${ }^{62}$ Separately, wash temperature and duration were tested to understand the effects of a cold, quick cycle compared to a longer, warmer cycle on MF release. This was undertaken at 200 RPM in $300 \mathrm{~mL}$ of water with $0.5 \mathrm{~mL}$ Ariel ${ }^{\circledR}$ liquid, also including a three-minute rinse (Table 3). The treatments were rotated between pots after each wash to eliminate any potential bias. To avoid contamination, the steel pots and arms of the tergotometer were thoroughly washed twice with deionised water before and in-between each washing run to remove any residual fibres. Both tests included a treatment of $0.5 \mathrm{~mL}$ Ariel ${ }^{\circledR}$ liquid at $30^{\circ} \mathrm{C}$ for one hour in $300 \mathrm{~mL}$ of water and $200 \mathrm{RPM}$ as a control. The wash and rinse water from each pot was transferred separately through a clean stainless-steel funnel into separate collection containers $(2 \mathrm{~L})$ free of plastic particles (confirmed by filtration onto Whatman ${ }^{\circledR} 541$ filter paper, G.E. Life Sciences, Little Chalfont, U.K). 
147 Filtration. The same filtration method was used throughout. The wash water was filtered 148 using a vacuum pump in two stages. Firstly, through a $20 \mu \mathrm{m}$ CellMicroSieve ${ }^{\circledR}$ (BioDesign Inc., 149 Carmel, N.Y., U.S.A.) collecting the MFs on the surface. This was required to remove excess 150 dye and detergent that was found to have previously interfered with MF quantification. In 151 addition, the use of the larger (25 cm in diameter) CellMicroSieve ${ }^{\circledR}$ reduced the effect of 152 clogging issues reported in previous methods. ${ }^{32,46,50}$ The MFs were then re-suspended in 153 clean water ( $1 \mathrm{~L}$ glass beaker) before a second filtration step onto white, $22 \mu \mathrm{m}$ pore size 154 Whatman ${ }^{\circledR} 541$ filter paper held using a Büchner funnel. The filter paper was placed in a 140 $155 \mathrm{~mm}$ diameter circular petri dish with the lid closed (VWR, code: 391-1503) to prevent dust 156 settling, that might cause contamination of the analysis, and left for 24 hours to dry at $50^{\circ} \mathrm{C}$. 


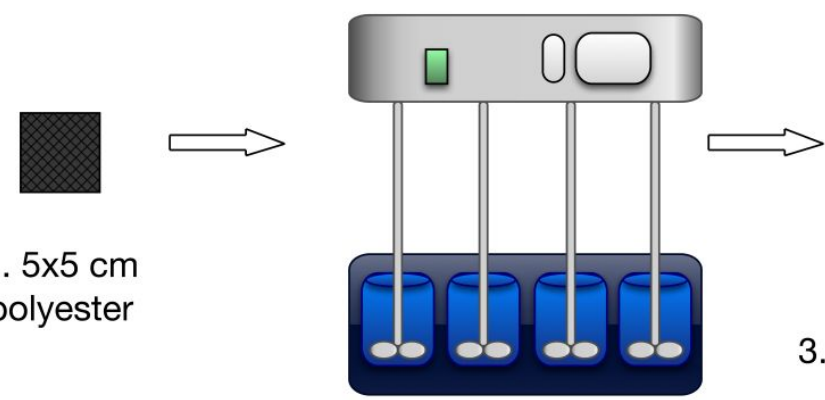

2. Tergotometer

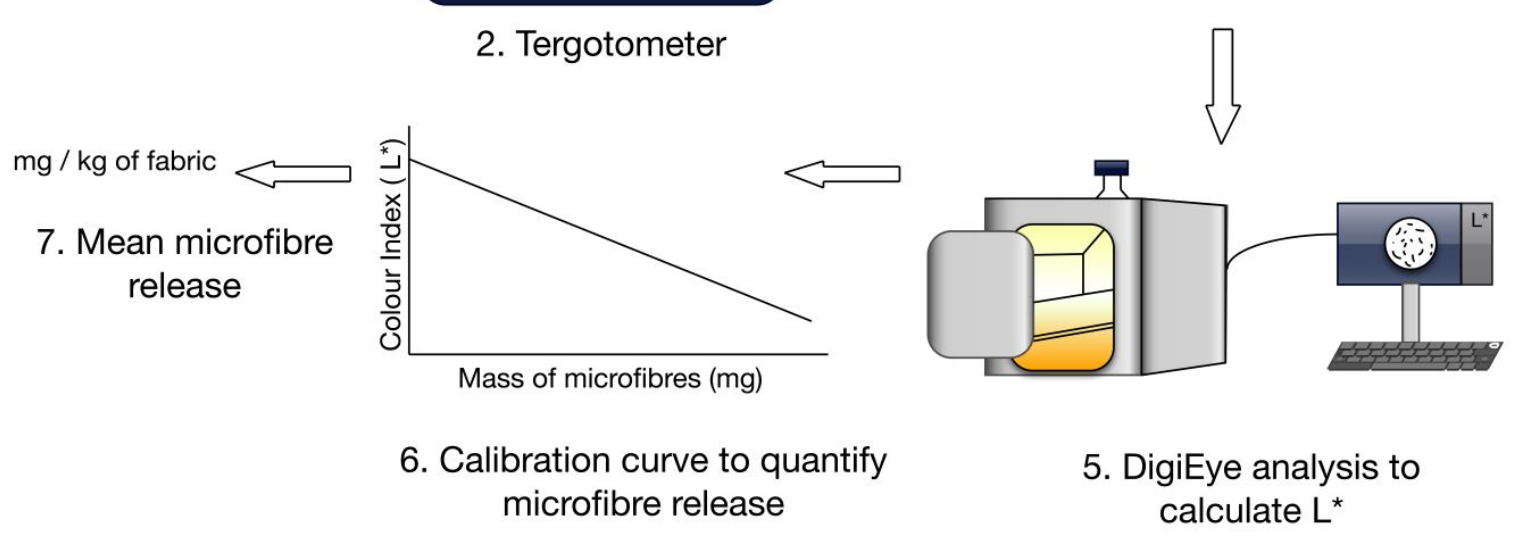

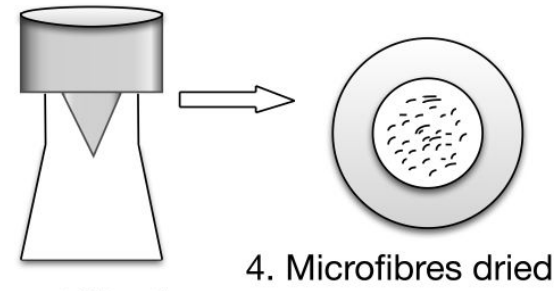

3. Two-part filtration for $24 \mathrm{~h}$

Figure 1. The small-scale method. 
159 Small-scale microfibre quantification. Each filter $(n=64)$ was imaged using DigiEye ${ }^{\circledR}$ image 160 capture machinery/software ${ }^{63}$ (VeriVide Ltd, Leicester, U.K.) to calculate an $L^{*}$ value (defined 161 below). This system uses a DSLR camera (shutter speed $1 / 2.5$, aperture width $7.1 \mathrm{~mm}$ ) to take 162 an image in a controlled D65 illumination cabinet, subsequently viewed on a calibrated LCD 163 monitor using Engauge Digitizer chart v 3.5. The camera was calibrated using the Digitizer 164 chart characterising the camera RGB signal response to the CIE specification under fixed 165 lighting conditions in the illumination cabinet. ${ }^{64} \mathrm{~A}$ fixed mask (area of analysis) was set over 166 the filter image using the 'fixed circle' tool with a radius of 750 pixels. The $L^{*}$ of each pixel is 167 calculated and the overall average was cross-correlated to a calibration curve (Figure 2) which 168 was made to calculate the mass of released MFs. Using mass, the number of released MFs 169 could then be estimated. 
170 Table 2. Treatment types for small-scale test 1: investigating agitation and water-volume ${ }^{a}$

\begin{tabular}{lll} 
Treatment & Volume $(\mathrm{mL})$ & Revolutions per minute (RPM) \\
\hline A & 300 & 200 \\
B & 600 & 200 \\
C & 300 & 100 \\
D & 600 & 100 \\
&
\end{tabular}

171

172 Table 3. Treatment types for small-scale test 2: investigating temperature and wash duration ${ }^{a}$

\begin{tabular}{lll} 
Treatment & Temperature $\left({ }^{\circ} \mathrm{C}\right)$ & Wash duration (minutes) \\
\hline E & 30 & 60 \\
F & 30 & 15 \\
G & 15 & 60 \\
H & 15 & 15
\end{tabular}

${ }^{a}$ Washes were carried out at 200 RPM in $300 \mathrm{~mL}$ of water with $0.5 \mathrm{~mL}$ Ariel ${ }^{\circledR}$ liquid. 
174 Calculating $L^{*} . L^{*}$ is a correlate of the perceived lightness of an object in the specified 175 illuminant defined by the International Commission on Illumination. ${ }^{58} \mathrm{It}$ is proportional to the 176 luminance of the sample. This value was obtained through the DigiEye ${ }^{\circledR}$ software by 177 calculating the RGB values of every pixel across the entire filter image and taking an overall 178 mean. The RGB values are then converted to XYZ D65/10 (measured XYZ values for D65 179 illuminant a 10-degree observer). This is the amount of red, green, and blue response of the 180 light sensitive cone cells of the eye needed to match the colour in the specified illuminant. $L^{*}$ 181 is measured using the $X Y Z$ directly. The $X Y Z D 65 / 10$ is converted to $L^{*}$ using equation $1 .{ }^{65}$

$$
L^{*}=116\left(\frac{y}{100}\right)^{\frac{1}{3}}-16
$$

Where $Y$ is a measure of the luminance scaled to 100. Therefore, a white that perfectly reflected the light source would have a $Y$ value of 100 and a perfect black would have a $Y$ value of 0 . The $L^{*}$ value therefore lies between $0-100$ which represents a scale from black $\left(L^{*}\right.$ $=0)$ to white $\left(L^{*}=100\right)$. This value can therefore be used as a proxy for the mass of MFs on a filter, as the colour measurement is governed by the concentration of MFs.

Calibration curve. A calibration curve was created by generating MFs from washing the textiles in the tergotometer before filtration (see above) onto filter paper and dried for 24 hours at $50^{\circ} \mathrm{C}$. Clusters of MFs were then removed from the filter paper with forceps and weighed using a thermogravimetric analyser, discovery model (TA Instruments, New Castle, U.S.A.), a microbalance which accurately records the mass as a function of time $(\approx$ five minutes) and temperature $\left(\approx 24^{\circ} \mathrm{C}\right)$ to four decimal places. Mass of MFs ranged from 0-11 mg. The clusters of MFs were then suspended in clean water ( $1 \mathrm{~L}$ glass beaker) and filtered onto new filter papers. Each filter paper $(n=49)$ was then imaged with DigiEye ${ }^{\circledR}$ and the $L^{*}$ 
197 values were recorded against the corresponding known mass (Figure 2). MF mass for 198 subsequent filters could then be calculated using equation 2 to correlate $L^{*}$ with mass (mg):

$$
\text { Mass }=\left(97.629-L^{*}\right) / 0.588
$$

200

201 All experimental $L^{*}$ values fell in-between the range of the calibration curve upper and lower 202 values. Four blank (no fibres) filter papers were also washed and dried before being imaged 203 in the DigiEye ${ }^{\circledR}$ to obtain an $L^{*}$ value for a mass of zero mg. No filter papers from experimental 204 testing with MFs had $L^{*}$ vales higher than the blank samples.

205 Quantification of the number of released microfibres. By correlating $L^{*}$ with the mass of 206 released MFs, the number of released MFs could then be calculated using equation 3 derived by Napper and Thompson: ${ }^{35}$

$$
N=\frac{(m t / D)}{\pi r^{2} l}
$$

210 Where $\mathrm{N}$ is the total number of released MFs, $\mathrm{mt}$ is the mass of fibres (calculated with $L^{*}$ and

211 the calibration curve), $D$ is the density $\left(1.38 \mathrm{mg} / \mathrm{mm}^{3}\right), r$ is the average radius of released MFs

$212(5.8 \pm 0.96 \mu \mathrm{m})$ and $\mathrm{I}$ is the average length of released MFs $(0.96 \pm 1.10 \mathrm{~mm})$ (Figure S3). 


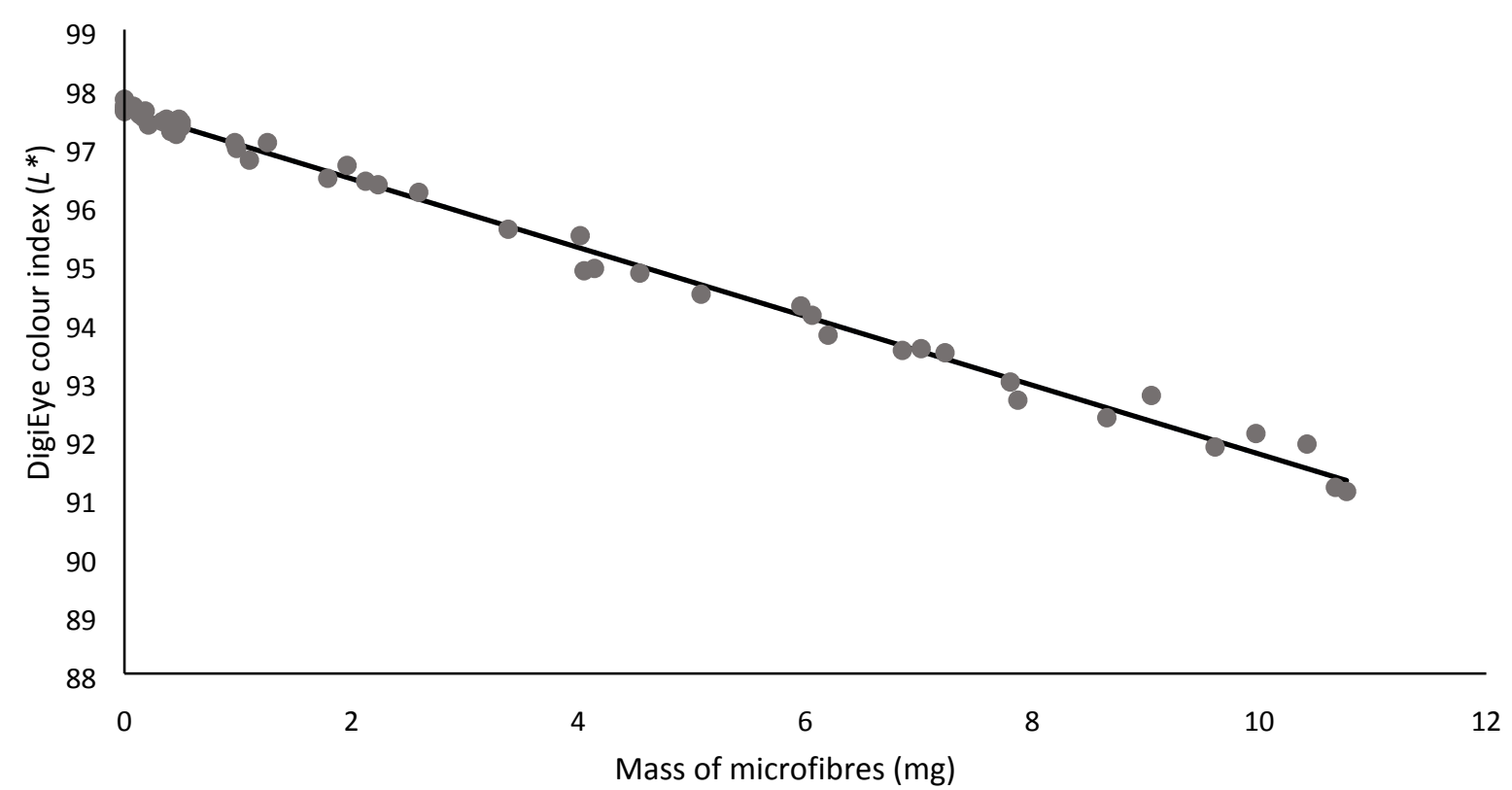

213

214 Figure 2. Microfibre calibration curve $(n=49)$. 
Full-scale washing procedure. Four treatments were tested (Table 4) over four cycles with four washing runs per cycle and no drying in-between cycles. For each washing run, all treatment types were tested in four separate identical washing machines resulting in four repeats of each treatment being washed per cycle. All treatments apart from treatment I

219 (Table 4) contained $35 \mathrm{~mL}$ Ariel ${ }^{\circledR}$ liquid to test the effect of detergent on MF release. Each single washing load consisted of 10 T-shirts $(1.5 \pm 0.01 \mathrm{~kg})$. Before testing, all washing machines were initially cleaned with a high temperature $\left(95^{\circ} \mathrm{C}\right)$ extended wash $(130$ minutes) ensuring no MFs were present (confirmed by filtration, as above). The waste water pipe was also cleaned following this to remove any residual fibres. After each washing run, the machines were cleaned by running a further 'wash out' cycle (cold express cycle) with no load to collect any residual fibres that were also filtered. The treatment type was then rotated to a different machine to eliminate potential bias. Water was collected for filtration and analysis on cycles one and four only; for cycles two and three, the wash water was discarded.

Full-scale microfibre collection and quantification. The wash water from each washing machine was collected directly from the outflow pipe and stored in plastic containers ( $25 \mathrm{~L}$ ) cleaned of MFs and any residual particles with hot water $\left(95^{\circ} \mathrm{C}\right)$, and filtered as above. The experimental filters $(n=32)$ containing the MFs were weighed on a microbalance (AE ADAM ${ }^{\circledR}$, Milton Keynes, U.K.) to four decimal places. To account for the change in filter mass after drying, ten blank filters were washed and weighed before and after drying, the change in mass $(\approx 1 \%)$ was averaged and applied to the mass of each recorded filter from the investigation. The average mass ( $\mathrm{mg}$ ) of fibres released per $\mathrm{kg}$ of textile washed was then calculated.

Quality assurance testing. To determine the amount of fibres remaining in the washing machine after a washing run, additional testing of 'blank' washes was carried out using the same textile in navy. Treatment II (Table 4) washing parameters were used on ten T-shirts in 
239 triplicate using three identical washing machines (same model used in full-scale washing).

240 MFs were collected from the wash and wash out step. An additional cycle (treatment II) was

241 then carried out with no fabric present and any residual MFs were filtered and weighed.

242 Statistical analysis. Data was checked for homoscedasticity using Levene's tests. Treatments

243 in the small-scale method met the assumption of homogeneous variance but treatments in

244 the full-scale method were $\log _{10}$ transformed to meet this assumption. Data from both

245 investigations were analysed using two-way ANOVA with 'treatment' (type of wash; 8 in the

246 small-scale, 4 in the full-scale) and 'cycle' (number of times that fabric had been washed;

247 either 1 or 4 ) as fixed, orthogonal factors. An alpha level of 0.05 was adopted, and Tukey's

248 post-hoc analyses were used to compare means of significant interactions or main-effects.

249 Results are presented as mean \pm standard error. All MF release rates are provided (Table S2). 
250 Table 4. Treatment types for full-scale testing ${ }^{a, b}$

\begin{tabular}{|c|c|c|c|}
\hline Treatment & Detergent & Cycle & Parameters of the cycle \\
\hline 1 & None & Cotton short cycle & 85 minutes, $1600 \mathrm{RPM}, 36 \mathrm{~L}, 30^{\circ} \mathrm{C}$ \\
\hline II & $35 \mathrm{~mL}$ Ariel ${ }^{\circledR}$ liquid & Cotton short cycle & 85 minutes, $1600 \mathrm{RPM}, 36 \mathrm{~L}, 30^{\circ} \mathrm{C}$ \\
\hline III & $35 \mathrm{~mL}$ Ariel ${ }^{\circledR}$ liquid & Cold Express & 30 minutes, $1600 \mathrm{RPM}, 30 \mathrm{~L}, 13-15^{\circ} \mathrm{C}$ \\
\hline IV & $35 \mathrm{~mL}$ Ariel ${ }^{\circledR}$ liquid & Delicate cycle & 59 minutes, $600 \mathrm{RPM}, 69 \mathrm{~L}, 30^{\circ} \mathrm{C}$ \\
\hline
\end{tabular}




\section{RESULTS AND DISCUSSION} curve was very high (0.9937) (Figure 2 ), showing that $L^{*}$ is an appropriate proxy for microscale estimations of MF release. Previous attempts to quantify MF release in small-scale studies have relied on labour-intensive manual enumeration of MFs using scanning electron microscopy ${ }^{36}$ or optical microscopy. ${ }^{44,46}$ To save time when counting large numbers of MFs in microscopy, the filter is sub-sampled and total fibres are estimated by scaling up. De Falco et al. ${ }^{36}$ accounted for MFs across $55 \%$ of the total filter, whereas Almroth et al. ${ }^{44}$ sub-sampled the filter into 16 equal areas. However, MFs do not have a uniform distribution across the filters (see for example, Figures S4 and S5), therefore sub-sampling may not be an accurate way of quantifying the total number of MFs. In contrast, DigiEye ${ }^{\circledR}$ images the entire filter, quantifying all MFs. Mcllwraith et al. ${ }^{66}$ discuss the advantages of sub-sampling five $50 \mathrm{~mL}$ aliquots to remove the need to count all MFs within a wash. However, fibres smaller than 100 $\mu \mathrm{m}$ could not be quantified and sub-sampled fibres were excluded from the overall weight of released fibres in the remaining effluent. Similarly, Hernandez et al. ${ }^{45}$ used two-dimensional binary imaging to estimate percentage cover of MFs. When converting in this way however, overlapping MFs are not detected resulting in an underestimation of MFs. When using $L^{*}$ an accurate measure of MFs is provided as a combination of reflectance, scatter, and adsorption of the fibres are measured. Thus, for a cluster of fibres, some light will be trapped in the spaces and some fibres will cast shadows over others; this results in multiple overlapping fibres being darker than single fibres, thus more accurately measuring clusters. Although testing with a single fabric is unlikely to represent real world laundry, single coloured fibres were used in this study, and also De Falco et al. ${ }^{51}$ in small-scale testing, in order to develop an experimental tool which can be used to experimentally investigate factors affecting MF 
release. To study mixed loads, a range of black garments could be tested; however, to study 'real world' loads as part of our future studies, a new calibration curve can be created in the same manner. The method is also applicable to light and dark coloured fibres providing the calibration curve is made with the same textiles used in testing. Transparent fibres would not be as suitable. DigiEye ${ }^{\circledR}$ can utilise the full RGB colour space; colour values $A^{*}$ and $B^{*}$ represent green-red and blue-yellow which could be used to quantify individual and total colour of real world laundry loads. Overlapping of mix coloured fibres would also produce a darker colour value than single fibres and could therefore be accounted for; however, there may be small variations in the colour values between different combinations of these overlapping fibres. Microscopy is required to obtain fibre dimensions (Figure S3), which are important when considering environmental, and human health impacts.

In addition to the analysis of the MFs, the novel application of the tergotometer does not require the use of steel balls or steel vessels to house the textiles, which may cause unrealistic MF release. ${ }^{36,44-46,51-52}$ The tergotometer used here simulates traditional central cone agitator top-loading washing machines. However, the detergent industry also uses them widely as model devices to simulate other types of washing machine through the development and validation of various parameters such as wash duration, agitation level and rotation pattern, and water:fabric ratio. The maximum spin speed (RPM) of the tergotometer arm was selected to understand the effect of high and low agitation. However, the ranges of temperature and duration possible using the tergotometer go beyond the parameters used in this study. In addition, the textiles were laser cut to thermally seal the edges, negating the need for serging. ${ }^{36,45,49,52}$ This is a necessary step when using swatches of textiles as the fabric needs to be cut. Therefore, loose fibres at the cut line may be released more easily than fibres in the 
yarn structure and provide an inaccurate measure of MF release. ${ }^{46}$ Thermally sealed edges reduce this potential artefact in the results.

301 Quality assurance testing. After the wash and wash out cycle during full-scale washing, an additional blank washing cycle was carried out (in triplicate) in order to quantify the level of residual fibres left in the machine. The amount of residual MFs collected during this extra wash was measured to be $<3 \%$ of the total mass of released MFs during the first cycle (Figure S6). This is within experimental error and therefore negligible. release were then investigated using the small-scale test. Water-volume was tested against mechanical agitation, which relates to the rotation speed of the drum, frequency of directional changes, and length of pauses in the cycle. This revealed significant differences in MF release across the treatments (Table S3; Figure 3). Treatment D used a high water-volume $(600 \mathrm{~mL})$ and low agitation (100 RPM), and resulted in a greater release of MFs compared to

312 all treatments except $\mathrm{B}$, which also used $600 \mathrm{~mL}$ (Figure 3 ). These findings highlight that a higher water-volume increases polyester MF release, whereas a higher mechanical agitation does not. These parameters (high water-volume/low agitation) are characteristic features of a 'delicate' wash cycle in European-style front-loading washing machines. ${ }^{53}$ For US machines,

316 a delicate cycle equivalent will use a lower agitation and spin speed, however the water 317 volume is not always changed. This region has traditionally used larger top-loading machines 318 with a high wash water-volume (64 $\mathrm{L}$ in the wash step alone)..$^{54-55}$

319 The observation that delicate wash-parameters released more MFs than 'normal' washing parameters is somewhat counterintuitive and has not been reported previously. In order to test whether observations made using the tergotometers were reflective of full-size domestic washing machines, an actual delicate wash cycle (treatment IV; Table 4) was then tested and 
also found to release significantly more MFs compared to other washes (Table S4; Figure 4).

A 'cotton short' programme (Table 4) was used as a 'normal' wash as this is one of the most frequently used programmes by consumers with European washing machines. ${ }^{62}$ Therefore, contrary to previous suggestions that higher mechanical agitation increases MF release, 48,50 ,

56-57 this work provides empirical evidence that water-volume is the more important driver of were used. In addition, there was no significant interaction between treatment and cycle number (Table S4), indicating that delicate washes still result in the highest MF release after at least four washes (Figure 4). Further testing is warranted to determine if this pattern continues throughout the whole life of a garment, but also to investigate the effect of watervolume on MF release in 'real world' mixed laundry loads. The physical characteristics of different textiles, such as their structure, can affect the release of MFs. ${ }^{50}$ Therefore additional testing will be needed to determine whether MF release also increases in consumer mixed loads as a result of higher water-volumes across a diverse range of cycle types. Results obtained with the small scale tergotometers are qualitatively similar to results seen in the larger washing machines. This means that the small-scale test method is a useful tool for future more in depth studies on factors which affect MF release during laundry. the textile weave. Individual MFs have a very large surface area to volume ratio, and consequently exhibit a low Reynolds number. ${ }^{67-68}$ As water passes through and over the fabric, each individual MF will experience extremely large viscous forces, which could act to pluck small fibres from the main textile weave. As delicate cycles also result in high MF release during subsequent washes, hydrodynamic forces may continue to weaken the yarn structure causing more loose fibres to be released from the yarn strand. Delicate washes increased MF 
347 release by $114 \mathrm{mg}$, or approximately $800,000 \mathrm{MFs}$ in the first wash (Table S2). This is 348 concerning since media groups have proposed greater adoption of delicate cycles as a way of 349 reducing MF release, citing 'mechanical stress' as an important factor with no experimental 350 evidence. ${ }^{56-57}$ If the results here are also true for a wider range of textiles then in addition to 351 using lower water-volume washes, switching to commercially available appliances that use 352 lower water-volumes regardless of wash type could also reduce MF release. Hartline et al. ${ }^{47}$ 353 reported a reduction in MFs when washing in front-loading machines compared to top354 loading machines. The study hypothesised that the central agitator in the top-loader maybe 355 more abrasive than drum rotation in the front-loading machine causing the increase in MF 356 release. However we show, for the first time, this difference could more likely be due to the 357 front-loading machine using a much lower water-volume. The global average annual water consumption for domestic washing is estimated at 19 billion $\mathrm{m}^{3}$, with North America representing the largest share (20\%). ${ }^{54,69-70}$ The use of high wash water-volumes in the 360 popular top-loading machines for North America could be a considerable factor for the high release of 3 million tonnes of MFs each year from the US. ${ }^{24,31}$ The transition to high-efficiency washing machines that use approximately $50 \%$ less water in the main wash ${ }^{55}$ is a necessary step to reduce water and electricity consumption. ${ }^{70}$ These data provide substantial evidence that this conversion would also greatly reduce MF release, and could therefore inform both manufactures and consumers to help reduce the environmental burden. For example, there are an estimated 840 million domestic washing machines worldwide ${ }^{69}$ with consumers not always using a full laundry load. ${ }^{62,70}$ If each user simply washed their laundry with full wash loads (decreasing water-volume-to-fabric ratio), it would not only have a positive benefit for energy and water consumption by reducing the number of washes, but could also reduce the amount of MFs entering the global environment per wash. 
371 Technologies proposed to reduce MF release have included the Lint LUV-R ${ }^{\odot}$ filter and the

372 Cora Ball ${ }^{\odot} .66$ However, the implementation of washing machine filters will be challenging and

373 may take additional time to have an impact while the use of the Cora Ball ${ }^{\odot}$ was found to

374 collect much fewer (26\%) MFs compared to the filter $(87 \%) .{ }^{66}$ On the other hand, simply

375 reducing the water-volume-to-fabric ratio would have an immediate effect. 


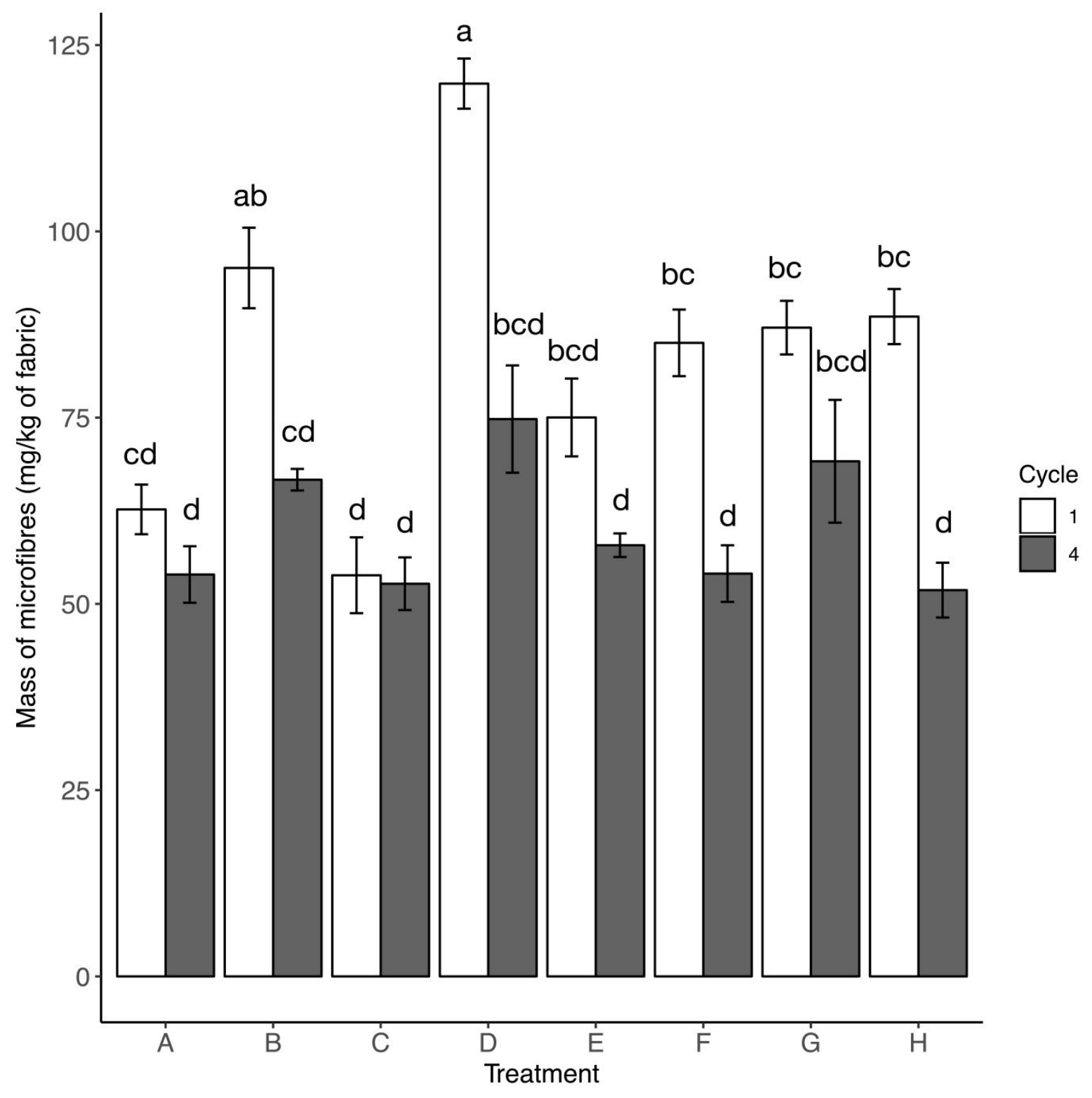

Figure 3. Mean mass $( \pm S E$ ) of released microfibres across seven different treatment types,

378 A (300 mL/200 RPM), B (600 mL/200 RPM), C (300 mL/100 RPM), D (600 mL/100 RPM) all

379 washed at $30^{\circ} \mathrm{C}$ for 60 minutes with detergent and treatments $\mathrm{E}\left(30^{\circ} \mathrm{C} / 60\right.$ minutes), $\mathrm{F}$

$380\left(30^{\circ} \mathrm{C} / 15\right.$ minutes $), \mathrm{G}\left(15^{\circ} \mathrm{C} / 60\right.$ minutes $)$, and $\mathrm{H}\left(15^{\circ} \mathrm{C} / 15\right.$ minutes $)$ all washed in $300 \mathrm{~mL}$ at

381200 RPM with detergent recovered during cycles one and four, for the small-scale

382 investigation (note. treatments A and E are the same). Groupings based on Tukey's post-hoc

383 analysis $(P>0.05)$; means that do not share a letter are significantly different. 
typically released compared to cycle one, although this was less pronounced in small-scale

386

387

388

389

390

391

392

393

394

395

396

397 tests compared to full-scale washing (Figures 3 and 4). At the small-scale, cycle one in treatments $D, B, F$, and $H$ released significantly more MFs than cycle four, but for the remaining treatments there was no significant difference. In the full-scale investigation, cycle one $(\bar{x}=124.37 \pm 14.40 \mathrm{mg} / \mathrm{kg})$ always resulted in a significantly greater release of MFs compared to cycle four $(\bar{x}=45.57 \pm 2.43 \mathrm{mg} / \mathrm{kg}$ ) (Table S4; Figure 4). The trend of decreasing MF release with increasing wash cycle is documented in the literature (Zambrano et al. ${ }^{52}$ ). Sillanpää and Sainio, ${ }^{37}$ found a large reduction in MF release from cycle one to five, for the majority of garments tested (mixture of polyester and cotton textiles). Napper and Thompson ${ }^{35}$ also found a decrease in MFs over subsequent cycles with little difference between cycles four and five for acrylic, polyester, and polyester-cotton textiles, which is comparable to Pirc et al. ${ }^{48}$ who reported a large initial spike in MF release for polyester fleece blankets, which then plateaued in the later cycles. De Falco et al. ${ }^{50}$ also reported a plateau in MF release after four washes for polyester fabric, whereas for a garment with a mixture of polyester/cotton/modal, MF release plateaued at cycle ten. Therefore fabric composition and structure also appear to affect MF release as the fabric ages. Thus although there is a possibility that MF release from additional unmonitored cycles two and three maybe higher than the delicate cycle (Figures 3 and 4), this is unlikely. The initial spike in fibre release may be from loose unbroken fibre debris from the yarn interior released in the first cycle. In contrast, Hernandez et al. ${ }^{45}$ found a steady release of $0.025 \mathrm{mg} / \mathrm{g}$ regardless of wash cycle; however, the use of steel balls in this study may increase MF release in the later cycles resulting in the consistent release over time. In addition, the method used included a prewash step which could have removed the initial spike of MFs. Hartline et al. ${ }^{47}$ found a $25 \%$ increase 
408 in MF release for older garments. In this work, the garments were mechanically aged by a 409 continuous washing cycle over 24 hours and this may not simulate the real aging of garments 410 when worn and washed. Therefore additional tests on real consumer loads which have been 411 both worn and washed over longer periods are needed to determine the effects of garment 412 age on MF release. If more MFs are released from the newer garments, particularly in the first 413 cycle, this could be mitigated using a filtered pre-wash after garment manufacturing. 


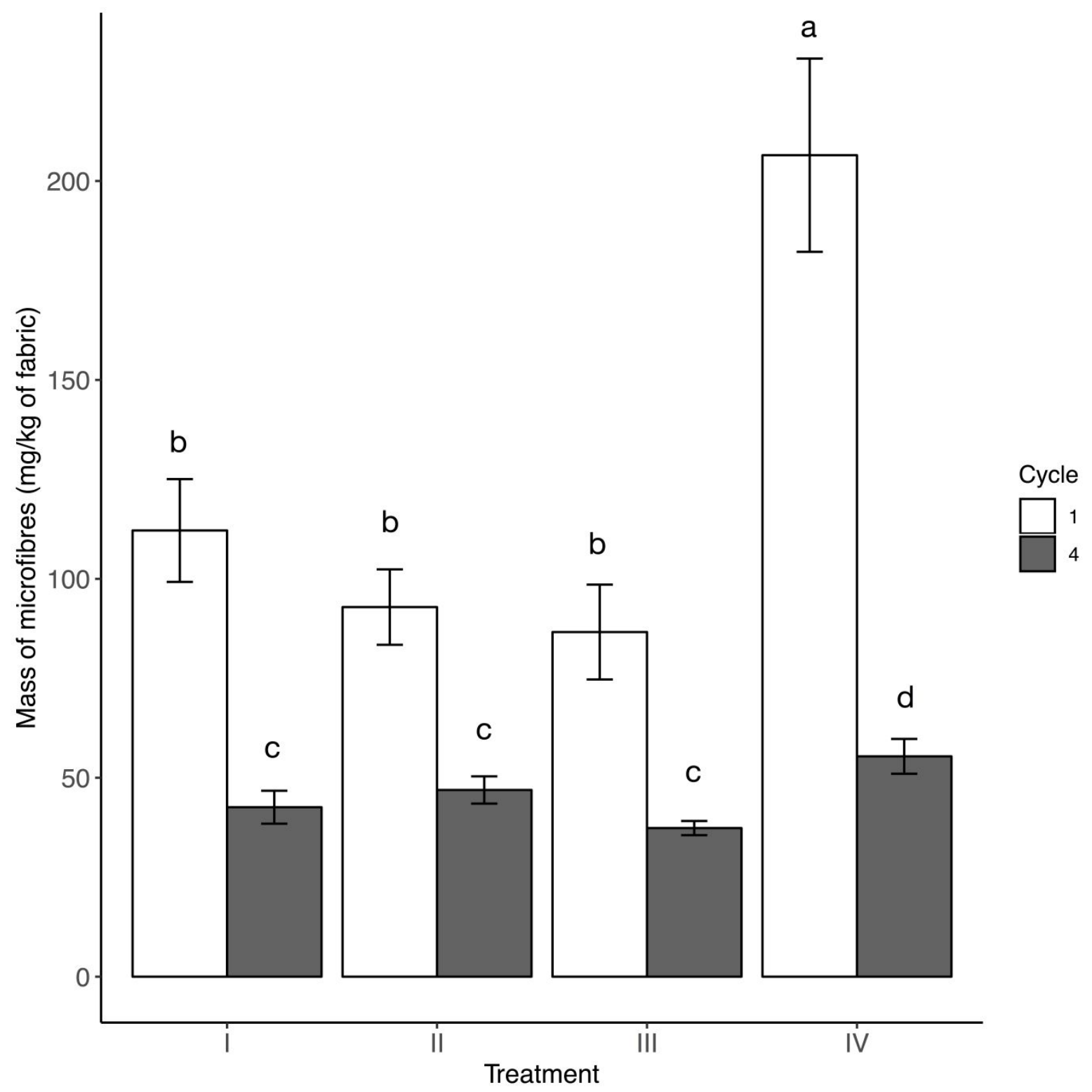

415

416 Figure 4. Mean mass $( \pm S E)$ of released microfibres across four different treatment types, I

$417\left(30^{\circ} \mathrm{C} /\right.$ cotton short/without detergent), II $\left(30^{\circ} \mathrm{C} /\right.$ cotton short/detergent), III (cold

418 express/detergent), and IV $\left(30^{\circ} \mathrm{C} /\right.$ delicate/detergent $)$ recovered during cycles one and four,

419 for the full-scale investigation. Groupings based on Tukey's post-hoc analysis $(P>0.05)$;

420 means that do not share a letter are significantly different. 
421 The effects of temperature and wash duration. At the small-scale, there were no significant

422 differences between treatments $E, F, G$, and $H$, suggesting the change in temperature and 423 wash duration $\left(15-30^{\circ} \mathrm{C} ; 15-60\right.$ minutes) had no impact on MF release (Figure 3; Table 3).

424 This is in agreement with Yang et al. ${ }^{49}$ who found low temperature (between $30^{\circ} \mathrm{C}$ and $40^{\circ} \mathrm{C}$ ) 425 had no impact on MF release, although higher temperatures $\left(60^{\circ} \mathrm{C}\right)$ increased $\mathrm{MF}$ release for 426 polyester fabric. Temperatures of $15^{\circ} \mathrm{C}$ and $30^{\circ} \mathrm{C}$ were chosen here as studies within the 427 literature have often tested at $30^{\circ} \mathrm{C}$ and above, therefore, not addressing the effects of 428 'colder' washes. Napper and Thompson ${ }^{35}$ found temperature was not consistent in affecting MF release, although between $30^{\circ} \mathrm{C}$ and $40^{\circ} \mathrm{C}$ there was an unspecified "increase" in 430 polyester MFs released compared to acrylic MFs. De Falco et al. ${ }^{36}$ found a non-statistically significant increase in $\mathrm{MF}$ release at $60^{\circ} \mathrm{C}$ compared to $40^{\circ} \mathrm{C}$ in plain weave polyester garments, and Hernandez et al. ${ }^{45}$ also testing polyester garments, found no significant difference in MF release across a wider range of temperatures between $25^{\circ} \mathrm{C}$ and $80^{\circ} \mathrm{C}$. It can

434 be concluded therefore, that temperature is not the most important factor affecting MF release, although increases may occur at higher $\left(60^{\circ} \mathrm{C}\right)$ to mid-temperature washes $436\left(30 / 40^{\circ} \mathrm{C}\right),,^{35-36}$ whereas below $30^{\circ} \mathrm{C}$ the change in MF release is less pronounced.

437 The 15 minute 'express' wash released as many fibres as 60 minute washes (Figure 3) which may indicate that the majority of MFs are released during the first 15 minutes of the wash. In

439 full-scale, the 'cold express' was comparable to full-length washes (Figure 4; Table 4). This 440 appears to support the hypothesis that loose MFs are hydro-mechanically 'plucked' from the 441 textile opposed to being broken from the weave over the course of the first wash. In the latter 442 cycles more fibres may have to be broken for any subsequent and continued release to be observed. In small-scale treatments F and H (15 minutes) there were significantly fewer MFs released in cycle four in contrast to $E$ and $G$ (60 minutes) where no differences were observed 
between cycles one and four. Hernandez et al. ${ }^{45}$ initially hypothesised that an increased mechanical agitation due to extended washing times would increase MF release; however, even by extending the wash to eight hours there was no significant increase. ${ }^{45}$ This suggests that mechanical agitation caused by drum rotation and drum speed is not a significant factor affecting MF release within a wash as previously mentioned, although shorter wash programmes may still reduce MF release in subsequent washes. Further studies are needed to establish how individual stages of the wash cycle (main wash, spin, and rinse) impact MF release.

The effect of detergent on microfibre release. Detergent had no effect on MF release (Table

4; Figure 4). This was consistent with Pirc et al., ${ }^{48}$ although Napper and Thompson, ${ }^{35}$ observed inconsistencies in MF release in the presence of a bio-detergent. Conversely, Hernandez et al., ${ }^{45}$ De Falco et al., ${ }^{36}$ Almroth et al., ${ }^{44}$ and Zambrano et al. ${ }^{52}$ found detergent leads to an overall increase in MF release, although these studies used steel balls which could mechanically interact with detergent causing unrealistic MF release. If the steel balls magnify the effects of detergent, perhaps by forcing it into the textile weave or agitating the surfactant so that more bubbles are produced, presumably there is some mechanism by which detergents increase MF release which did not manifest in the present study. Further investigations into detergent type and their interactions with different textiles are probably warranted, but studies should use real-world conditions to keep results relevant. In conclusion, we have developed a method for quantifying MF release in small-scale conditions which qualitatively reflects the outcomes observed in full-sized domestic washing machines. The small- and full-scale method both indicate a higher water-volume increases MF release, temperature and duration have no significant effect, and MF release is greatest in the first cycle. As public awareness of plastic pollution and the overall anthropogenic 

environmental impact increases, domestic laundry is an important emerging target for

470 reducing the global environmental burden. Changes in domestic laundry behaviour could help

471 to address the UN sustainable development goals (SDG) 14, 'life below water' and 15 'life on

472 land'. ${ }^{71}$ This study shows that if consumers can adopt lower water-volume washes or

473 transition to lower water-volume washing machines, and increase wash load size (number of

474 garments per wash), this would prevent substantial quantities of plastic MFs from entering 475 the environment.

476

477 ASSOCIATED CONTENT

478 Supporting Information

479 Summary of factors affecting microfibre release (Table S1), description and image of the 480 tergotometer (Figure S1), small-scale experimental design (Figure S2), fibre metrics, fibre 481 measurements (Figure S3), all release rates (Table S2), images of released microfibres in the 482 full-scale investigation, cycle one (Figure S4), and cycle four (Figure S5), images of released 483 microfibres from quality assurance testing (Figure S6), Two-Way ANOVA statistics for small484 scale (Table S3) and full-scale (Table S4) testing 485

486 AUTHOR INFORMATION

487 Corresponding Author

488 *E-mail: grant.burgess@newcastle.ac.uk

489

490 ORCID

491 Max R. Kelly: 0000-0002-7136-0527

492 Neil J. Lant: 0000-0002-5939-0125 
493 Martyn Kurr: 0000-0001-6649-024X

494 J. Grant Burgess: 0000-0002-1491-7341

495

496 Funding Sources

497 This work was funded by the Engineering and Physical Sciences Research Council (U.K.) and 498 Procter and Gamble through an Industrial CASE studentship (EP/R512047/1).

499

$500 \quad$ Notes

501 N.J.L. is employed by Procter and Gamble, a manufacturer of detergents and other fabric care 502 products.

503

504 Acknowledgments

505 We would like to thank Mick Butterworth for his technical advice using DigiEye ${ }^{\circledR}$. 
507 (1) Haward, M., Plastic pollution of the world's seas and oceans as a contemporary

508 challenge in ocean governance. Nat. Commun. 2018, 9 (1), 667-669.

(2) Lee, J.; Lee, J. S.; Jang, Y. C.; Hong, S. Y.; Shim, W. J.; Song, Y. K.; Hong, S. H.; Jang, M.;

510 Han, G. M.; Kang, D., Distribution and size relationships of plastic marine debris on beaches

511 in South Korea. Arch. Environ. Contam. Toxicol. 2015, 69 (3), 288-298.

512 (3) Gall, S. C.; Thompson, R. C., The impact of debris on marine life. Mar. Pollut. Bull. 2015, $51392(1), 170-179$.

(4) Worm, B.; Lotze, H. K.; Jubinville, I.; Wilcox, C.; Jambeck, J., Plastic as a persistent 515 marine pollutant. Annu. Rev. Environ. Resour. 2017, 42, 1-26.

516 (5) Provencher, J. F.; Bond, A. L.; Avery-Gomm, S.; Borrelle, S. B.; Rebolledo, E. L. B.;

517 Hammer, S.; Kühn, S.; Lavers, J. L.; Mallory, M. L.; Trevail, A., Quantifying ingested debris in

518 marine megafauna: a review and recommendations for standardization. Anal. Methods $519 \quad 2017,9(9), 1454-1469$.

(6) De Stephanis, R.; Giménez, J.; Carpinelli, E.; Gutierrez-Exposito, C.; Cañadas, A., As main

521 meal for sperm whales: Plastics debris. Mar. Pollut. Bull. 2013, 69 (1-2), 206-214.

522 (7) Ivar do Sul, J. A.; Costa, M. F., The present and future of microplastic pollution in the 523 marine environment. Environ. Pollut. 2014, 185, 352-64.

524 (8) Ribeiro, F.; O’Brien, J. W.; Galloway, T.; Thomas, K. V., Accumulation and fate of nano525 and micro-plastics and associated contaminants in organisms. TrAC, Trends Anal. Chem.

$5262018,111,139-147$. 
(9) De Souza Machado, A. A.; Kloas, W.; Zarfl, C.; Hempel, S.; Rillig, M. C., Microplastics as an emerging threat to terrestrial ecosystems. Glob. Chang. Biol. 2018, 24 (4), 1405-1416.

529 (10) Lin, V. S., Research highlights: impacts of microplastics on plankton. Environ. Sci.: Processes Impacts 2016, 18 (2), 160-163.

531 (11) Napper, I. E.; Bakir, A.; Rowland, S. J.; Thompson, R. C., Characterisation, quantity and 532 sorptive properties of microplastics extracted from cosmetics. Mar. Pollut. Bull. 2015, 99 (1), $533 \quad 178-185$.

534 (12) Boucher, J.; Friot, D. Primary Microplastics in the Oceans: a Global Evaluation Of 535 Sources; IUCN, Gland, Switzerland, 2017; p 43. polymers floating in the marine environment. Environ. Sci.: Processes Impacts 2015, 17 (9), 1513-1521.

(14) De Witte, B.; Devriese, L.; Bekaert, K.; Hoffman, S.; Vandermeersch, G.; Cooreman, K.;

540 Robbens, J., Quality assessment of the blue mussel (Mytilus edulis): Comparison between 541 commercial and wild types. Mar. Pollut. Bull. 2014, 85 (1), 146-155.

542 (15) Rochman, C. M.; Tahir, A.; Williams, S. L.; Baxa, D. V.; Lam, R.; Miller, J. T.; Teh, F.-C.; 543 Werorilangi, S.; Teh, S. J., Anthropogenic debris in seafood: Plastic debris and fibers from 544 textiles in fish and bivalves sold for human consumption. Sci. Rep. 2015, 5, 14340.

545 (16) Murray, F.; Cowie, P. R., Plastic contamination in the decapod crustacean Nephrops 546 norvegicus (Linnaeus, 1758). Mar. Pollut. Bull. 2011, 62 (6), 1207-1217. 
547 (17) Lusher, A. L.; McHugh, M.; Thompson, R. C., Occurrence of microplastics in the 548 gastrointestinal tract of pelagic and demersal fish from the English Channel. Mar. Pollut.

549 Bull. 2013, 67 (1-2), 94-9.

550 (18) Torre, M.; Digka, N.; Anastasopoulou, A.; Tsangaris, C.; Mytilineou, C., Anthropogenic 551 microfibres pollution in marine biota. A new and simple methodology to minimize airborne 552 contamination. Mar. Pollut. Bull. 2016, 113 (1-2), 55-61.

553 (19) Zhao, S.; Zhu, L.; Li, D., Microscopic anthropogenic litter in terrestrial birds from 554 Shanghai, China: Not only plastics but also natural fibers. Sci. Total Environ. 2016, 550, 11105551115.

556 (20) Gusmão, F.; Di Domenico, M.; Amaral, A. C. Z.; Martínez, A.; Gonzalez, B. C.; Worsaae, 557 K.; do Sul, J. A. I.; da Cunha Lana, P., In situ ingestion of microfibres by meiofauna from 558 sandy beaches. Environ. Pollut. 2016, 216, 584-590.

559 (21) Watts, A. J.; Urbina, M. A.; Corr, S.; Lewis, C.; Galloway, T. S., Ingestion of plastic 560 microfibers by the crab Carcinus maenas and its effect on food consumption and energy 561 balance. Environ. Sci. Technol. 2015, 49 (24), 14597-14604.

562 (22) Jemec, A.; Horvat, P.; Kunej, U.; Bele, M.; Kržan, A., Uptake and effects of microplastic 563 textile fibers on freshwater crustacean Daphnia magna. Environ. Pollut. 2016, 219, 201-209.

564 (23) Gray, A. D.; Weinstein, J. E., Size-and shape-dependent effects of microplastic 565 particles on adult daggerblade grass shrimp (Palaemonetes pugio). Environ. Toxicol. Chem. $5662017,36(11), 3074-3080$. 
567

568

569

570

571

572

573

574

575

576

577

578

579

580

581

582

583

584

585

586

(24) Miller, R. Z.; Watts, A. J.; Winslow, B. O.; Galloway, T. S.; Barrows, A. P., Mountains to the sea: river study of plastic and non-plastic microfiber pollution in the northeast USA.

Mar. Pollut. Bull. 2017, 124 (1), 245-251.

(25) Lusher, A. L.; Burke, A.; O’Connor, I.; Officer, R., Microplastic pollution in the

Northeast Atlantic Ocean: validated and opportunistic sampling. Mar. Pollut. Bull. 2014, 88 (1-2), 325-333.

(26) Taylor, M.; Gwinnett, C.; Robinson, L.; Woodall, L., Plastic microfibre ingestion by deep-sea organisms. Sci. Rep. 2016, 6, 33997-34005.

(27) Jamieson, A. J.; Brooks, L. S. R.; Reid, W. D. K.; Piertney, S. B.; Narayanaswamy, B. E.; Linley, T. D., Microplastics and synthetic particles ingested by deep-sea amphipods in six of the deepest marine ecosystems on Earth. R. Soc. Open Sci. 2019, 6 (2), 180667.

(28) Kole, P. J.; Löhr, A. J.; Van Belleghem, F.; Ragas, A., Wear and tear of tyres: a stealthy source of microplastics in the environment. Int. J. Environ. Res. Public Health 2017, 14 (10), 1265.

(29) Salvador Cesa, F.; Turra, A.; Baruque-Ramos, J., Synthetic fibers as microplastics in the marine environment: A review from textile perspective with a focus on domestic washings. Sci. Total Environ. 2017, 598, 1116-1129.

(30) Waller, C. L.; Griffiths, H. J.; Waluda, C. M.; Thorpe, S. E.; Loaiza, I.; Moreno, B.;

Pacherres, C. O.; Hughes, K. A., Microplastics in the Antarctic marine system: an emerging area of research. Sci. Total Environ. 2017, 598, 220-227. 
587 (31) Mishra, S.; charan Rath, C.; Das, A. P., Marine microfiber pollution: a review on 588 present status and future challenges. Mar. Pollut. Bull. 2019, 140, 188-197.

589 (32) Browne, M. A.; Crump, P.; Niven, S. J.; Teuten, E.; Tonkin, A.; Galloway, T.; Thompson, 590 R., Accumulation of microplastic on shorelines woldwide: sources and sinks. Environ. Sci.

591 Technol. 2011, 45 (21), 9175-9179.

592 (33) Murphy, F.; Ewins, C.; Carbonnier, F.; Quinn, B., Wastewater Treatment Works 593 (WwTW) as a Source of Microplastics in the Aquatic Environment. Environ. Sci. Technol. $5942016,50(11), 5800-8$.

595 (34) De Villiers, S., Microfibre pollution hotspots in river sediments adjacent to South 596 Africa's coastline. Water SA 2019, 45 (1), 97-102.

597 (35) Napper, I. E.; Thompson, R. C., Release of synthetic microplastic plastic fibres from 598 domestic washing machines: Effects of fabric type and washing conditions. Mar. Pollut. Bull. 599 2016, $112(1-2), 39-45$.

600 (36) De Falco, F.; Gullo, M. P.; Gentile, G.; Di Pace, E.; Cocca, M.; Gelabert, L.; Brouta601 Agnesa, M.; Rovira, A.; Escudero, R.; Villalba, R.; Mossotti, R.; Montarsolo, A.; Gavignano, S.; 602 Tonin, C.; Avella, M., Evaluation of microplastic release caused by textile washing processes 603 of synthetic fabrics. Environ. Pollut. 2018, 236, 916-925.

604 (37) Sillanpää, M.; Sainio, P., Release of polyester and cotton fibers from textiles in 605 machine washings. Environ. Sci. Pollut. Res. 2017, 24 (23), 19313-19321.

606 (38) Carr, S. A., Sources and dispersive modes of micro-fibers in the environment. Integr. 607 Environ. Assess. Manag. 2017, 13 (3), 466-469. 
(39) Krifa, M.; Stevens, S. S., Cotton Utilization in Conventional and Non-Conventional

609 Textiles-A Statistical Review. Agric. Sci. 2016, 7 (10), 747-758.

610 (40) L'Abbate, P.; Dassisti, M.; Cappelletti, G. M.; Nicoletti, G. M.; Russo, C.; Ioppolo, G.,

611 Environmental analysis of polyester fabric for ticking. J. Clean. Prod. 2018, 172, 735-742.

612 (41) Chen, R.; Jakes, K. A., Cellulolytic biodegradation of cotton fibers from a deep-ocean

613 environment. J. Am. Inst. Conservat. 2001, 40 (2), 91-103.

614 (42) Sanchez-Vidal, A.; Thompson, R. C.; Canals, M.; de Haan, W. P., The imprint of

615 microfibres in southern European deep seas. PloS one 2018, 13 (11), e0207033.

616 (43) Stanton, T.; Johnson, M.; Nathanail, P.; MacNaughtan, W.; Gomes, R. L., Freshwater

617 and airborne textile fibre populations are dominated by 'natural', not microplastic, fibres.

618 Sci. Total Environ. 2019, 666, 377-389.

619 (44) Almroth, B. M. C.; Åström, L.; Roslund, S.; Petersson, H.; Johansson, M.; Persson, N.-

620 K., Quantifying shedding of synthetic fibers from textiles; a source of microplastics released

621 into the environment. Environ. Sci. Pollut. Res. 2018, 25 (2), 1191-1199.

622 (45) Hernandez, E.; Nowack, B.; Mitrano, D. M., Polyester Textiles as a Source of

623 Microplastics from Households: A Mechanistic Study to Understand Microfiber Release

624 During Washing. Environ. Sci. Technol. 2017, 51 (12), 7036-7046.

625 (46) Jönsson, C.; Levenstam Arturin, O.; Hanning, A.-C.; Landin, R.; Holmström, E.; Roos, S.,

626 Microplastics shedding from textiles-developing analytical method for measurement of

627 shed material representing release during domestic washing. Sustainability 2018, 10 (7),

$628 \quad 2457-2473$. 
629 (47) Hartline, N. L.; Bruce, N. J.; Karba, S. N.; Ruff, E. O.; Sonar, S. U.; Holden, P. A., 630 Microfiber Masses Recovered from Conventional Machine Washing of New or Aged

631 Garments. Environ. Sci. Technol. 2016, 50 (21), 11532-11538.

632 (48) Pirc, U.; Vidmar, M.; Mozer, A.; Krzan, A., Emissions of microplastic fibers from 633 microfiber fleece during domestic washing. Environ. Sci. Pollut. Res. 2016, 23 (21), 2220663422211.

635 (49) Yang, L.; Qiao, F.; Lei, K.; Li, H.; Kang, Y.; Cui, S.; An, L., Microfiber release from 636 different fabrics during washing. Environ. Pollut. 2019, 249, 136-143.

637 (50) De Falco, F.; Di Pace, E.; Cocca, M.; Avella, M., The contribution of washing processes 638 of synthetic clothes to microplastic pollution. Sci. Rep. 2019, 9 (1), 6633.

639 (51) De Falco, F.; Gentile, G.; Di Pace, E.; Avella, M.; Cocca, M., Quantification of 640 microfibres released during washing of synthetic clothes in real conditions and at lab scale.

641 Eur. Phys. J. Plus 2018, 133 (7), 257.

642

(52) Zambrano, M. C.; Pawlak, J. J.; Daystar, J.; Ankeny, M.; Cheng, J. J.; Venditti, R. A.,

643 Microfibers generated from the laundering of cotton, rayon and polyester based fabrics and 644 their aquatic biodegradation. Mar. Pollut. Bull. 2019, 142, 394-407.

645 (53) Mendelson, C., Laundry: The home comforts book of caring for clothes and linens.

646 Simon and Schuster: New York, 2009.

647 (54) Pakula, C.; Stamminger, R., Electricity and water consumption for laundry washing by 648 washing machine worldwide. Energy Effic. 2010, 3 (4), 365-382. 
649 (55) Chen-Yu, J. H.; Emmel, J., Comparisons of fabric care performances between

650 conventional and high-efficiency washers and dryers. Fashion Text. 2018, 5 (1), 19.

651 (56) Microfiber release from clothes after washing: Hard facts, figures and promising

652 solutions. https://www.plasticsoupfoundation.org/wp-content/uploads/2017/08/Position-

653 Paper.Microfiber-release-from-clothes-after-washing.PSF .pdf (accessed 26 January 2019).

654 (57) Microfibres: what we know so far. https://www.rei.com/blog/news/microfibers-what-

655 we-know-so-far (accessed 28 January 2019).

656 (58) International Commission on Illumination. Colorimetry Part 4: CIE $1976 L^{*} a^{*} b^{*}$ Colour 657 Space (ISO 11664-4) 2008.

658 (59) Harris, J. C., Detergency evaluation. III. Adjustment of Terg-O-Tometer and 659 launderometer wash test methods to produce comparable soil removal data. J. Am. Oil 660 Chem.' Soc. 1952, 29 (3), 110-113.

661 (60) Leenerts, L. O.; Pietz, J. F.; Elliott, J., Soil removal by dishwashing detergents. J. Am. Oil 662 Chem.' Soc. 1956, 33 (3), 110-122.

663 (61) Denawaka, C. J.; Fowlis, I. A.; Dean, J. R., Source, impact and removal of malodour 664 from soiled clothing. J. Chromatogr. A 2016, 1438, 216-225.

665 (62) Kruschwitz, A.; Karle, A.; Schmitz, A.; Stamminger, R., Consumer laundry practices in 666 Germany. Int. J. Consum. Stud. 2014, 38 (3), 265-277.

667 (63) Luo, M.; Cui, C.; Li, C., British patent (Application No. 0124683.4) entitled apparatus 668 and method for measuring colour (DigiEye ${ }^{\circledR}$ System). Derby University Enterprises Limited 6692001. 
670 (64) Matusiak, M., Digieye application in cotton colour measurement. Autex. Res. J. 2015, $67115(2), 77-86$.

672 (65) Tkalcic, M.; Tasic, J. F., Colour spaces: perceptual, historical and applicational 673 background. IEEE Region 8 Eurocon Conference, Computer as a Tool: 2003; Vol. 1, p 304674308.

675 (66) Mcllwraith, H. K.; Lin, J.; Erdle, L. M.; Mallos, N.; Diamond, M. L.; Rochman, C. M., 676 Capturing microfibers-marketed technologies reduce microfiber emissions from washing 677 machines. Mar. Pollut. Bull. 2019, 139, 40-45.

678 (67) Happel, J.; Brenner, H., Low Reynolds number hydrodynamics: with special 679 applications to particulate media. Springer Science \& Business Media: The Hague, 680 Netherlands, 2012; Vol. 1.

681 (68) Purcell, E. M., Life at low Reynolds number. Am. J. Phys. 1977, 45 (1), 3-11.

682 (69) Barthel, C.; Götz, T. The overall worldwide saving potential from domestic washing 683 machines. With results detailed for 10 world regions. http://www.bigee.net/media/filer public/2013/03/28/bigee domestic washing machines _worldwide potential 20130328.pdf. (accessed 1 February 2019). washing processes. Energy Effic. 2015, 8 (2), 205-222. Nations, 2015. 